\title{
Fate of Tricuspid Valve Five Years after Left Heart Valve Replacement
}

\author{
Anbarasu Mohanraj, Saikumari Nagaraj, Rekha Arunagiri, Rajan Sethurathinam, VM Kurian \\ From World Society of Cardiothoracic Surgeons 25th Anniversary Congress, Edinburgh \\ Edinburgh, UK. 19-22 September 2015
}

\section{Background/Introduction}

Residual functional tricuspid regurgitation can cause significant symptoms after a successful left heart valve replacement surgery. There is more evidence towards repairing moderate tricuspid valve regurgitation of late.

\section{Aims/Objectives}

We analysed the fate of Tricuspid valve at the end of five years after a left heart valve replacement irrespective of whether they had undergone a concomitant TV repair or not during the initial surgery

\section{Method}

Between January 2008 and December 2009, 200 patients who had undergone a left heart valve replacement were analysed for the degree of TV regurgitation at the end of five years. 162 patients had undergone a Mitral valve surgery and 38 patients had undergone a double valve replacement. Group I - 40 patients had a concomitant TV repair (Modified de Vaga's annuloplasty) during the primary surgery and Group II 160 patients did not have a concomitant TV repair.

\section{Results}

In Group I, of the 40 patients, 4 patients (10\%) underwent TV repair for moderate TV regurgitation, and all the 4 patients had trivial to mid TV regurgitation. 36 patients underwent TV repair for severe regurgitation, of these patients, 30 patients $(83.3 \%)$ had trivial to mild residual TV regurgitation, while only 6 patients $(16.6 \%)$ had moderate to severe TV regurgitation. In Group II, of the 160 patients, 58 patients $(36.2 \%)$ and 16 patients $(10 \%)$ had moderate and severe TV regurgitation which was left un-corrected. Of the 58 patients who had moderate TV regurgitation, 20 patients (34.4\%) had moderate regurgitation and 4 patients

Institute of Cardio Vascular Diseases, Madras Medical Mission, Chennai, India
(6.8\%) had severe TV regurgitation at the end of five years. Of the 16 patients who had severe TR addressed during the initial surgery, 8 patients (50\%) had moderate to severe TV regurgitation at the end of five years.

\section{Discussion/Conclusion}

A concomitant Tricuspid valve repair is recommended during a left heart valve replacement, if the degree of Tricuspid regurgitation is moderate. This helps in alleviating the symptoms of residual tricuspid valve regurgitation on long term follow up.

Published: 16 December 2015

doi:10.1186/1749-8090-10-S1-A21

Cite this article as: Mohanraj et al:: Fate of Tricuspid Valve Five Years after Left Heart Valve Replacement. Journal of Cardiothoracic Surgery 2015 10(Suppl 1):A21.

\section{Submit your next manuscript to BioMed Central and take full advantage of: \\ - Convenient online submission \\ - Thorough peer review \\ - No space constraints or color figure charges \\ - Immediate publication on acceptance \\ - Inclusion in PubMed, CAS, Scopus and Google Scholar \\ - Research which is freely available for redistribution

